\title{
Editorial
}

\section{Reflections on biodiversity and food supply: from the nano to the macro-political}

TW Lukes once observed that '[t]he discursive script of environmentality embedded in terms such as ecology or environment is rarely articulated by scientists or technical analysts. Yet there are politics here'. ${ }^{1}$ While many readers of this edition of the Journal of Human Rights and the Environment would not necessarily find themselves in agreement with a committed Foucauldian reading of the complex relationships characterising the domain of 'biodiversity and food supply', it is nonetheless essential not to overlook the very real presence, signalled by the various contributions to this edition, of the 'politics here'.

Prima facie, most of the contributions in this edition focus on matters that could easily be characterised as technical and/or regulatory. Several of the authors reflect, for example, on a range of complexities, structural characteristics and interrelationships concerning various normative and regulatory frameworks: the regulation of food labelling with respect to nano-particles (Stokes); the detailed mechanics of the relationship between Art 27.3b of the World Trade Organization's (WTO) Trade-related Aspects of Intellectual Property Rights (TRIPS) and the Convention on Biological Diversity (McMahon); and the regulatory and discursive structure of the WTO (Smith). Additionally, we are offered an analysis of lessons to be drawn from participatory scenarios within an empirical research project on UK food system vulnerabilities in the light of systems transition theory (Lee and Marsden). While Theriault offers more overtly political reflection on the environmental justice implications of the relationship between Inuit food security and rights discourse, it is true to say that in each of the contributions to this edition our attention is drawn, in various ways, to the densely woven threads of the political and its critique. There is a definite sense in which the contributions suggest (with apologies to Lukes) that while 'the discursive script of juridical and market power embedded in terms such as sustainability and conservation is rarely articulated by the technocrats of legal, economic and environmental regulation' there is, indeed, a (sometimes observably pernicious) 'politics here'.

Familiar macro-political themes emerge in this edition of the Journal of Human Rights of the Environment. These include the ideological and political closure enacted by global corporate dominance; the exclusionary effects of neo-liberal market liberalisation; the epistemological rupture and material inequalities between the global North and the global South; the ambivalent effects of conservation interventions; the urgency and virtual impossibility of achieving the transformative shift required in the face of business-as-usual; the Gordian complexity of systemic interactions; the normative and conceptual incoherence of environmental regulation; the gulf between the putative goals of global regulatory frameworks and their measurable impacts at local level; the

1. TW Luke, Capitalism, Democracy and Ecology: Departing from Marx (University of Illinois, Illinois 1999) at 131 (emphasis original). 
environmental injustices resulting from the priorities of market-industrialism - and the particular vulnerability to the effects of the anthropogenic sources of climate change of those who contribute to it least. We can also discern a theme concerning the inequalities both reflected by and enacted through the discursive construction of the 'other', specifically the discursive construction of the 'indigenous' as 'victim' within an ideology of international paternalism. There is, importantly, an almost inevitable sense in which the issue of biodiversity and food supply draws our attention to the most bio-material aspects of environmental and human injustice and exclusion.

Human rights and environmental considerations converge in the ultimate dependency of food supply and quality upon biodiversity. There is an intimate nexus, for example, between food quality, environmental and ecological balance, human survival/flourishing and the basic viability of human societies. Reflecting upon this in the present globalised context draws our attention to (as is clearly implied by contributions to this edition) a counter-productive epistemic rupture between the relatively monocultural paradigm informing current regulatory structures and the more diverse and open ecologies of knowledge pluralities necessary in the context of the global crisis facing us. Such epistemic dissonance is clearly reflected, for example, in Theriault's contribution. Taking a human rights-based perspective of food security as her starting point, Theriault stresses the co-constitutive relationship between the human, cultural and environmental reflected in the issue of the food insecurity faced by the Inuit populations of the Arctic region. Her account points to the epistemological closure and cultural insensitivity implicated in biodiversity conservation strategies which counter-productively both foster and hamper Inuit resilience and food security. Bringing an environmental justice perspective to bear, Theriault argues, brings into focus processes of marginalisation implicating issues of power related to post-colonial (and presumably also 'neo-colonial') dynamics. In response to this, she stresses the centrality of 'agency': the central claim being that '[f]rom a normative standpoint, environmental justice requires that marginalised communities, groups and individuals who are particularly affected by environmental degradation should have agency in the decision-making processes that are likely to affect their environmental rights and interests'.

Smith extends the notion of indigenous agency and participation to imply that indigenous methods are fundamental to the very preservation of biodiversity itself - that, in other words, indigenous communities should have a right of participation, not just in relation to their own food security and the preservation of local biodiversity, but as equal partners in the global search for biodiversity and a secure food supply. Smith's argument takes as its starting point the example of peasant and family farm organisations that deploy the notion of rights combined with an emphasis on indigenous agro-ecological technique as a model for addressing the challenge of biodiversity preservation. The forum in which indigenous expectations are located, however, is the WTO. Smith concedes that this makes a certain kind of sense (in so far as state practices with regard to subsidy use and other trade mechanisms do have a systemic effect on the livelihood and productivity of indigenous farmers) but she cautions that the WTO is unlikely to address the concerns of small-scale producers. Linking the subsidisation of agriculture with large-scale monoculture (and its deleterious effect upon biodiversity), Smith argues that the WTO free-market paradigm discursively excludes the full implications of the argument put forward by indigenous peasant and family farm organisations. The true subjects of WTO rules, she argues, are states, and in the final analysis any WTO protection given to indigenous farmers and their interests is 'incidental': Rights, in the full sense, simply do not accrue to indigenous 
farmers within the WTO scheme. Accordingly, the clear implication of Smith's analysis is that the WTO discursive structure turns upon a form of exclusionary state-centrism resistant to the potential role of indigenous farmers in the generation of solutions to the global problems facing biodiversity and food supply: the conceptual and linguistic closure is just too overwhelming to allow for their genuine inclusion as subjects within the WTO framework.

A common theme emerging in these contributions is arguably the dissonance observable between the stated goals of regulatory frameworks and the thin (or suppressed) agency of excluded (in these cases, 'indigenous') populations. The themes of agency and participation also find a place in the contribution of Stokes, whose argument reflects a concern for the participatory empowerment of populations made up of a more complex amalgam of interest groups and consumer-citizen identities. Stokes focuses on the topic of nanomaterials - and in particular, nanofoods. Contextualising her discussion against a breakdown in trust between the public and the regulatory bodies charged with the policy management of public health risks, Stokes argues that the contemporary confidence crisis reflects not just past failures, such as the BSE scare, but the fact that the 'impenetrable and abstruse language of risk marginalises broader social and political considerations'. This arguably approaches a paradigmatic case of the Foucauldian closure invoked by Lukes above, and reflected, albeit in refracted ways, in the contributions of both Theriault and Smith. Stokes links technical regulatory and rhetorical culture with a distinct marginalisation, or muting, of the political. This 'political', moreover, resonates with a potential epistemic crisis likely to affect both human rights and environmental considerations: the angst and uncertainty surrounding the emergence and evolution of biotechnological artefacts which challenge the very intelligibility of the category of the 'natural' taken to be foundational to conceptions of human rights and the environment alike. In relation to nanofoods, anxieties are pervasive: Stokes points out that the Food Standards Agency describes the 'overall tone of public attitudes towards new technologies [as] "one of wariness, unease, uncertainty, and sometimes outright negativity". In a strategy akin to that of Theriault and Smith, Stokes points to the importance of civil society involvement as a means of addressing the anxieties attending risk management practices, lack of public trust and public suspicion of technocratic regulatory policy. However, notwithstanding the demonstrable need for one, there is no coordinated programme of public engagement in this area. Instead (perhaps predictably given the market's status as the ever-present ideological driver of the dominant contemporary social normativity), a particular 'modality of citizen action' has emerged, channelled through market transactions. Stokes suggests that proposals concerning the mandatory labelling of nanofoods can be interpreted, against this background, as a limited participatory model predicated on a right to consumer information, or consumer choice - but also goes further, signalling, arguably, some return of the 'political' by drawing on the potentially more robust notion of 'consumer voice'. The political or civic subject formed in this context is, however, a clustered amalgam of identities: 'consumer'/'market-player'/'citizen'/'participant in everyday life' - a subject with limitations reflecting the all-too-familiar presence of market forms and logics. Stokes points out that the capacity of the nanolabel to promote decisional autonomy alongside 'market citizenry' is limited (or, we could argue, 'further limited') by the characteristics of the 'choice environment' itself. One significant result of the policy focus on consumer choice (combined with deficiencies in the choice setting) is precisely the foreclosure of opportunity for broader debate concerning the social and ethical ramifications of nano-based products. Yet, it is clear that such issues have the 
greatest possible relevance for both human rights and the environment and they require urgent interrogation. Stokes's conclusion, however, suggests that the issues at stake are unlikely to be adequately addressed by nanolabelling, which in the final analysis can only alert consumers 'to the sheer uncertainty' facing us.

Future uncertainty is also reflected in Lee and Marsden's contribution, which combines systems transition theory and participatory empirical research in order to explore the need for, and potential nature of, a food system transition, and to explore a future crisis of food security in the United Kingdom. In light of the concerns discussed above, Lee and Marsden's observations concerning the centrality of participation and inclusion in the search for effective solutions are particularly telling. They point to the genuine usefulness of the insights produced by participatory engagement, which offers 'considerable opportunity for policy-learning' - an observation lending further support to the claim that the genuine participation of a range of stakeholders, affected parties and epistemological standpoints in addressing the crisis that faces us is not only necessary but more likely to be productive. Lee and Marsden suggest that the UK food system has key vulnerabilities, lacks the resilience to respond to them and may face a future security crisis, despite the present impression that food is plentiful and relatively cheap in the UK. They identify the need for a fundamental transformation involving the rebalancing of the productive capacity of the global (and UK) food system - a transformation firmly established upon ecological, social and environmental imperatives and values. However, a central implication of their work is the difficulty of achieving this, despite the need for a fundamental shift being clear.

In methodological terms, Lee and Marsden deploy transitions theory as a paradigm through which to design and understand empirical, participatory studies exploring future food security scenarios. What emerges from their research is the Gordian complexity of accounting for the mix of endogenous and exogenous factors in play: from consumer resistance and loss of markets, for example, to the fundamental incoherence of socio-technological regimes in the agro-food system itself - and much, much more besides. Revealingly, Lee and Marsden conclude that their research reveals the need for more carefully attuned, reflexive governance frameworks. Arguably, the fundamental openness and responsiveness implied by the notions of 'attunement' and 'reflexivity' point, yet again, to themes of inclusivity and participation, and towards the fundamental need to move away from closure and hegemony towards frameworks of thought, response and action radically open to both complexity and to variant epistemic positions/locations. Indeed, Lee and Marsden identify the main source of difficulty in considering food system transitions as being the closure and power of the dominant paradigm itself.

The sheer difficulty of achieving transition or change (even in the face of challenges as urgent as human malnutrition and environmental degradation (and which are so often implicated in the relationship between biodiversity and food supply)) is further reflected in McMahon's contribution. McMahon offers an in-depth account of the fractured negotiations involved in a much-needed review of Article 27.3 (b) of the WTO's TRIPS Agreement concerning the patenting of plants and animals and the protection of plant varieties and its relationship with the Convention on Biological Diversity (CBD). McMahon's analysis fully implies, it is suggested, the change-inhibiting macro-political closures of the dominant paradigm which attend the interplay between human rights and the environment - in this case, the transformation-resistant fault-lines visible between the global North and global South concerning the nature of the relationship between TRIPS and the CBD, and between an 'old World-new World' concerning 'geographical indications' with respect to the multilateral register 
for wines and spirits, and the related question of extending the treatment afforded to wines and spirits to other products.

The issues at stake beneath McMahon's painstaking account of the negotiations could scarcely be more serious in their implications for both human beings and the environment. McMahon underlines this fact when he cites a 2010 communication to the TRIPS Council from Bolivia - which argues for an 'in-depth and accelerated review of Article 27.3 (b)' in response to what can be characterised as a litany of human and environmental abuses within the agriculture industry. The challenge facing the still on-going review is profound, and the heart of the matter, arguably, concerns justice in the global trading system with respect to the conservation and sustainable use of biological resources, matters focally concerning the asymmetrically disadvantaged nations of the global South. Conceptual contradictions and asymmetries abound, and McMahon's careful analysis suggests that there is no guarantee that the genuine complexities and ethical concerns these put into play will be adequately addressed any time soon. His elegant tracing of the labyrinthine twists and turns of the Doha negotiations and their failure to complete a review of Article 27.3(b) amply suggests the Gordian nature of the challenges facing the future - and further emphasise the very real influence of a familiar (and dominant) 'politics here'.

Anna Grear (Co-Editor in Chief) Director, Global Network for the Study of Human Rights and the Environment (GNHRE), Bristol Law School, UWE Bristol, UK 